\title{
On spline collocation and the Hilbert transform
}

\section{SANDA MiCULA}

\section{ABSTRACT.}

In this paper we examine a relationship between the spline collocation projection operator $\pi_{n}$ and the Hilbert singular integral operator $\mathcal{H}_{0}$. We use Fourier analysis to prove that under certain conditions, a commutator property holds between the two operators. More specifically, we show that for $u \in H^{t},\left\|\left(\pi_{n} \mathcal{H}_{0}-\mathcal{H}_{0} \pi_{n}\right) u\right\|_{t} \leq$ $C h^{\lambda}\|u\|_{s}$ (where $h=1 / n$ ), for some $t, s$ and $\lambda \in \mathbb{R}$.

\section{REFERENCES}

[1] Adams, R. A., Sobolev Spaces, Academic Press, New York/San Francisco/London, 1975

[2] Anttila, J., A spline collocation method for parabolic pseudodifferential equations, J. Comput. Appl. Math., 140 (2002), No. 1-2, 41-61

[3] Arnold, D. N. and Wendland, W. L., The Convergence of Spline Collocation for Strongly Elliptic Equations on Curves, Numer. Math., 47 (1985), No. 3, 317-341

[4] Efendiev, M. A. and Wendland, W. L., Nonlinear Riemann-Hilbert problems with Lipschitz continuous boundary data: Doubly connected domains, R. Soc. Lond. Proc. Ser. A Math. Phys. Eng. Sci., 459 (2003), 945-955

[5] Grigorieff, R. D., Additional order convergence in qualocation for elliptic boundary integral equations, J. Integral Equations Appl., 23 (2011), No. 3, 383-419

[6] King, F. W., Hilbert Transforms: Volume 1, Cambridge University Press, 2009

[7] Micula, Gh. and Micula, S., Handbook of Splines, Kluwer Academic Publishers, Dordrecht/Boston/London, 1999

[8] Micula, S., On Superconvergent Spline Collocation Methods for the Radiosity Equation, Stud. Univ. Babeş-Bolyai Math., 51 (2006), No. 4, 145-156

[9] Micula, S. and Micula, Gh., On the Superconvergent Spline Collocation Methods for the Fredholm Integral Equations on Surfaces, Math. Balkanica (N.S.), 19 (2005), No. 1-2, 155-166

[10] Prößdorf, S. and Schneider, R., Spline approximation methods for multidimensional periodic pseudodifferential equations, Integral Equations and Operator Theory, 15 (1992), No. 4, 626-672

[11] Saranen, J. and Vainikko, G., Periodic Integral and Pseudodifferential Equations with Numerical Approximation, Springer-Verlag, Berlin/Heidelberg/New York, 2002

[12] Saranen, J. and Wendland, W. L., The Fourier series representation of pseudodifferential operators on closed curves, Complex Variables Theory Appl., 8 (1987), No. 1-2, 55-64

Department of MATHEMATiCs AND COMPUter SCIENCE

BABEŞ-BOLYAI UNIVERSITY

M. KOGĂLniCEANu 1, 400084 Cluj-NAPOCA, Romania

E-mail address: smicula@math.ubbcluj.ro

Received: 03.07.2013; In revised form: 08.01.2014; Accepted: 23.04.2014

2010 Mathematics Subject Classification. 35J60, 41A15, 42A16, 46F12, 47G30, 65R10.

Key words and phrases. Spline collocation, Hilbert transform, Fourier analysis. 